\title{
Nickel-Containing Alloys for Medical Application Obtained by Methods of Mechanochemistry and Powder Metallurgy
}

\author{
D. D. Radev \\ Institute of General and Inorganic Chemistry, BAS, “Acad. G. Bonchev" Street, Bl.11, Sofia 1113, Bulgaria \\ Correspondence should be addressed to D. D. Radev, ddradev@gmail.com
}

Received 3 October 2012; Accepted 19 October 2012

Academic Editors: T. Czujko, Y. Hao, and P. Markovsky

Copyright (C 2012 D. D. Radev. This is an open access article distributed under the Creative Commons Attribution License, which permits unrestricted use, distribution, and reproduction in any medium, provided the original work is properly cited.

The methods of mechanochemistry, in combination with cold pressing and pressureless sintering, were used to obtain the most popular nickel-based and nickel-containing alloys used in dentistry and implantology. It was shown that the intense mechanical treatment of $\mathrm{Ni}, \mathrm{Ti}$, and $\mathrm{Cr}$ powders used as reagents, and the application of the above-mentioned simple powder metallurgical technique for densification allows obtaining $\mathrm{NiCr}$ and $\mathrm{NiTi}$ alloys with controlled structural properties. The nickel-based dental alloys obtained by mechanically activated sintering possess excellent mechanical, technological, and aesthetic properties. These alloys are suitable as dental restorative materials and for production of porcelain veneered constructions like crowns and bridges using the so-called metal-to-ceramic dental technique. It was shown that the method of mechanically assisted synthesis allows obtaining nanosized NiTi alloy at significantly lower temperature in comparison with the traditional high-temperature alloying. It was also shown that after 40 hours intense mechanical treatment of reagents, a direct synthesis of NiTi alloy proceeds. The product has excellent sinterability which enables to produce bodies with controlled porosity appropriate for application in implantology.

\section{Introduction}

The range of traditional application of nickel-based alloys covers different areas that require high performance at elevated temperatures. The formation of continuous matrix austenitic $\gamma$ phase, that usually contains various percentages of $\mathrm{Cr}, \mathrm{Mo}, \mathrm{W}, \mathrm{Fe}$, and $\mathrm{Co}$, the presence of coherently precipitating $\gamma^{\prime}$ phases, and carbide or boride grain boundary segregates gives possibilities to form variety of alloys working at extremely high temperatures subjected to a combination of mechanical stresses and thermal shocks. The large number of Ni-based superalloys and the multiplicity of their properties and areas of application are a good example in this respect. Due to the attractive combination of good mechanical properties, chemical resistivity and biocompatibility Ni-based alloys also find a broad application in the fields of dentistry and implantology. Nickel-chromium and nickeltitanium alloys are the most popular representatives in these two medical branches.

1.1. Nickel-Chromium Dental Alloys. Dental alloys could be categorized as noble, containing as a main element gold or palladium and base nickel or cobalt metal alloys [1]. The significant increases of the noble metals price since 1960s stimulate the development of nonprecious nickelbased dental alloys. Nowadays Ni-based alloys used in dentistry have become superior to the gold-based alloys in hardness, elasticity, tensile strength, and particularly in their prices [2]. The ideal dental alloy is biocompatible, and possesses high mechanical strength and corrosion resistance. These alloys also have low prices, appropriate value of the thermal expansion coefficient conformable to that of the veneering ceramic mass, and good technological and aesthetic properties. The current nickel-based dental alloys are multicomponent systems containing in addition to the main metals of $\mathrm{Ni}, \mathrm{Cr}$, and Mo (totally about 90-95 wt.\%) also elements like $\mathrm{Be}, \mathrm{Mn}, \mathrm{Nb}$, and $\mathrm{Si}$ (5-10 wt\% totally) and some additives like Ce, B, C, and $\mathrm{N}$ in amounts of part of the percent. Dental alloys are traditionally prepared by consequent melting and thermal alloying of their components in the form of cylindrical ingots weighting 5-10 g. Using centrifugal lost-wax casting of pellets and metal-toceramic techniques for porcelain veneering, different dental constructions such as crowns and bridges are produced. 
The homogeneity of the multicomponent melt and the exact composition of every pellet are of decisive importance for processes of production and for the quality of the end dental constructions. The traditional method of thermal alloying and casting of nickel-chromium dental alloys is characterized by significant difficulties in obtaining products with constant composition. The considerable differences in the melting and boiling points and densities of the starting components strongly impede to obtain homogeneous melt in the process of thermal alloying and consequently to achieve equal and desired composition and the corresponding set of properties of each dental alloy ingot/pellet. To maintain the high level of similar production processes, expensive melting techniques and strict composition control of every dental pellets batch are required.

1.2. Nickel-Titanium Alloys. The effects of shape memory, two-way shape memory, and superelasticity are among the remarkable properties for equiatomic NiTi or some close in composition NiTi-based alloys. These characteristics are based on the martensitic transformation and its reversion and can be provoked by thermal or mechanical impact. These alloys show an unexpectedly low elastic anisotropy and as a consequence very high ductility determining a cold working up to $60 \%$. The excellent biocompatibility and the high corrosion resistance resulting from the stable $\mathrm{TiO}_{2}$ layers formation are other remarkable properties of $\mathrm{NiTi}$ alloys. The combination of these unique properties makes NiTi the most successful commercial shape-memory alloys [3]. In the last decade these alloys have attracted much interest as functional materials, sensors and actuators, guide wires, medical devices and surgical tools, orthodontic wires, and so forth. Spring-like temperature sensitive stents for cardio-vascular surgery produced from shape-memory NiTi alloy are a good example in that respect. Compressed and supercooled stent is inserted into the artery where under the influence of the human body temperature it recovers its initial shape, thus expanding the blood vessel. The Ni-based shape memory alloys (SMAs) attracted also attention for their potential use as implants because of their appropriate from a medical viewpoint, mechanical properties, and the technological possibility to obtain bodies with a porous microstructure similar to that of the human bone tissue. The traditional method of NiTi synthesis includes serial technological steps such as melting, hot rolling, cold rolling, intermediate annealing, and final cold rolling. During these processes the high-temperature oxidation causes material losses and degradation of the product properties [4]. The described disadvantages make the traditional metallurgical method for synthesis of NiTi time consuming and reduced their economical efficiency.

Here we show how to overcome disadvantages of the traditional metallurgical methods in obtaining Ni-containing alloys with application in dentistry and implantology. The methods of mechanically assisted synthesis and sintering are based on intense milling of components of alloys. In combination with cold pressing and sintering or thermal treatment, high-quality Ni-based dental alloys and NiTi SMAs have been obtained.

\section{Experimental}

Figure 1 shows SEM of the initial nickel particles used in the synthesis of Ni-based dental alloys. The Ni powder is produced by Novamet using carbonyl synthesis method. The particles have regular globular shape and mean particle size of 3-5 $\mu \mathrm{m}$. As a result of their chemical purity and small particle size, characteristic of the carbonyl synthesis method, these particles have very high sinterability. Chromium particles with mean particle size $150-200 \mu \mathrm{m}$ were obtained by milling of chromium lumps ( $99.9 \%$ purity) and as a consequence of the mechanical impact have an absolutely flat shape.

Figure 2 shows a mixture of initial $\mathrm{Ni}-20 \% \mathrm{Cr}$ particles used as main components in synthesis of multicomponent nickel-based dental alloy. Molybdenum powder with mean particle size of $5.0 \mu \mathrm{m}$ was obtained by double hydrogen reduction of $\mathrm{MoO}_{3}$ at $1100^{\circ} \mathrm{C}$. Ni-based dental ingots containing $\mathrm{Cr}$ and Mo-95.0\%, totally and the rest to $100 \%$ : Si (Elkem Silicon Materials), $\mathrm{Mn}$, and Ce, were obtained by mechanical treatment of reagents, cold pressing of the homogeneous powdery mixture at $15.0 \mathrm{GPa}$ to obtain pellets with desire shape. These green bodies were vacuum sintering at $1295^{\circ} \mathrm{C}$ for $30 \mathrm{~min}$ to achieve high density ingots. Using lost-wax centrifugal casting method, standard bars suitable for mechanical tests were produced. These tests included Vickers hardness $\left(H V_{10}\right)$, tensile strength $(R m)$, elongation limit $\left(R p_{0.2}\right)$, and ductile yield $\left(A_{5}\right)$. The thermal expansion coefficient of the Ni-based alloy was determined by dilatometric measurements in the temperature range $20-600^{\circ} \mathrm{C}$. Using the same casting method and metal-toceramic technique for porcelain veneering, different dental constructions appropriate to evaluate the technological and aesthetic properties of the alloy were produced.

Titanium powder (98.5\% purity) obtained by Fluka and $\mathrm{Ni}$ particles with globular shape and particle size below $10 \mu \mathrm{m}$ obtained by hydrogen reduction at $600^{\circ} \mathrm{C}$ of $\mathrm{NiO}$ (black) were used as reagents for the syntheses of equiatomic NiTi alloys. Figure 3 shows SEM of the initial Ti powder used in the synthesis of NiTi.

The particles have smooth shape and most of them are interconnected. The size of aggregates and some separated particles exceeds $250 \mu \mathrm{m}$. Ni and Ti powders in atomic ratio $1: 1$ were mixed and mechanically treated in a planetary ball mill (Pulverizette 5/4, Fritsch $\mathrm{GmbH}$ ) up to $40 \mathrm{~h}$ at a rotation speed of $200 \mathrm{rpm}$. Stainless steel bowls $\left(80 \mathrm{~cm}^{3}\right)$ and balls with a diameter of $10 \mathrm{~mm}$ and total volume of $25 \mathrm{~cm}^{3}$ were used. In this way about $30 \%$ of the reactor volume was kept free of charge, thus ensuring optimal contact between milling bodies and metal particles, and thus achieving highly efficiency of the mechanical treatment. The milling containers were fitted with semipass flaps allowing mechanical treatment of metal powders under protective Ar atmosphere, thus preventing metal particles from oxidation. Some amount of reagents was removed periodically 


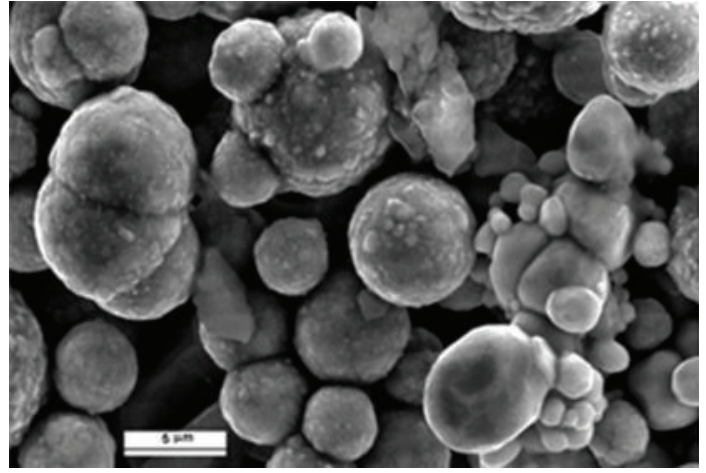

FIgURE 1: SEM image of starting Ni particles, $\times 4500$.

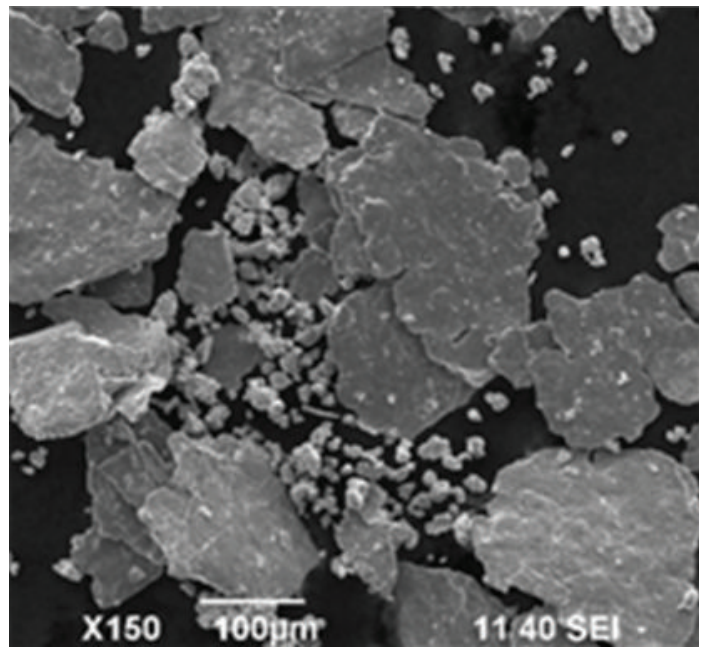

FIGURE 2: SEM image of starting NiCr powder mixture $(3: 1), \times 150$.

for structural and phase analyses. The mechanically assisted thermal synthesis of NiTi alloy was carried out after $30 \mathrm{~h}$ intense mechanical treatment of reagents in a corundum tube furnace in a hydrogen stream at $550^{\circ} \mathrm{C}$ for $30 \mathrm{~min}$. Sintering of dense NiTi bodies with controlled porosity was performed at $800^{\circ} \mathrm{C}$ under protective hydrogen atmosphere.

\section{Results and Discussion}

3.1. Ni-Based Dental Alloys. Figure 4 shows SEM image of Ni-20wt.\% Cr powder mixture after 6 hours intense mechanical treatment in a planetary ball mill. The picture reveals globular aggregates with mean size of about $70-80 \mu \mathrm{m}$ consisting of submicrometric particles.

This is a typical view of mechanically treated plastic metal particles and demonstrates the morphological and structural changes resulted by the mechanical impact. Homogenization and crashing of particles, appearance of highly reactive oxygen-free surfaces, accumulation different types of structural defects, development of the processes of plastic deformation, and cold welding leading to formation of aggregates are among the effects of mechanically treated solids. Similar morphological pictures were observed after

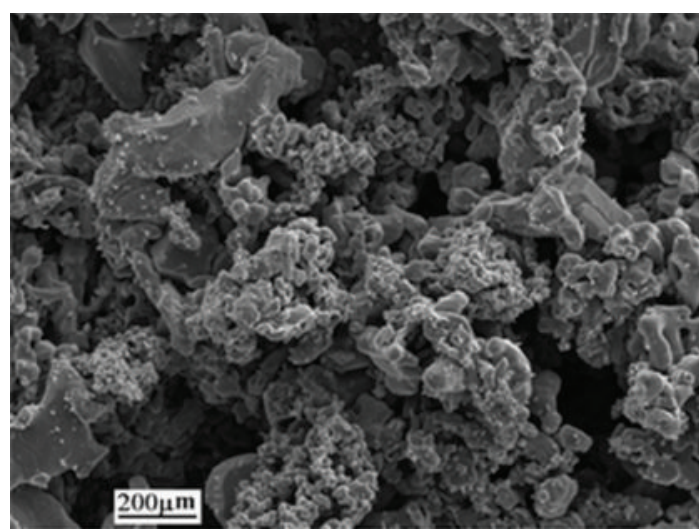

FIgure 3: SEM image of starting Ti particles, $\times 100$.

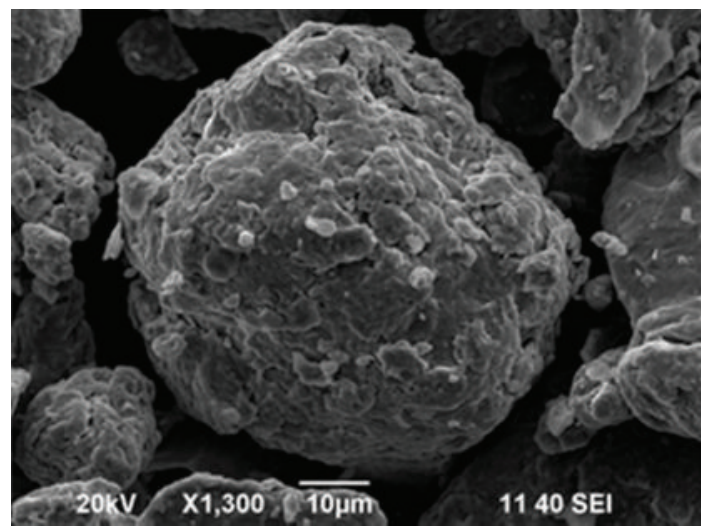

FIGURE 4: SEM image of $\mathrm{NiCr}$ after $4 \mathrm{~h}$ mechanical treatment, $\times 1300$.

intense mechanical treatment of $\mathrm{Ti}-\mathrm{Ni}$ and $\mathrm{TiB}$ powders in high energetic apparatuses like SPEX and planetary mills [5-7]. The formation of globular aggregates containing components of the alloy is very important from technological point of view for successful implementation of the coldpressing sintering processes and achievement of dental pellets with maximal density. Sintering of dental alloy pellets with almost theoretical density is decisive for the lost-wax casting process during which the end dental constructions are formed. The eventual presence of pores and cavities in the structure of the pellets leads to oxidation and slag formation during the process of dental construction casting. The practice of the powder metallurgy implies that $\mathrm{Cr}$ particles shown in Figure 2 would have poor pressability and sinterability resulting from their flat shape and big sizes. As a consequence, the powder mixture inherited the low sinterability of the $\mathrm{Cr}$ particles. The low density of the ingots is a precondition for bad quality of the end dental construction. The homogeneous distribution of $\mathrm{Ni}$ and $\mathrm{Cr}$ particles after mechanical treatment is demonstrated in Figure 5.

The BSEI image is obtained from the metallographic section of mechanically treated $\mathrm{Ni}-\mathrm{Cr}$ powder mixture. The content of $\mathrm{Ni}$ and $\mathrm{Cr}$ exceeds $85 \mathrm{wt} \%$ which makes 


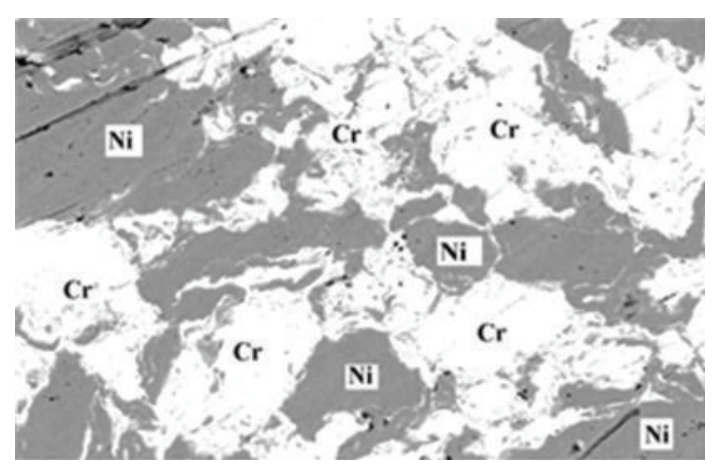

FIGURE 5: BSEI image of NiCr after $4 \mathrm{~h}$ mechanical treatment, $\times 500$.

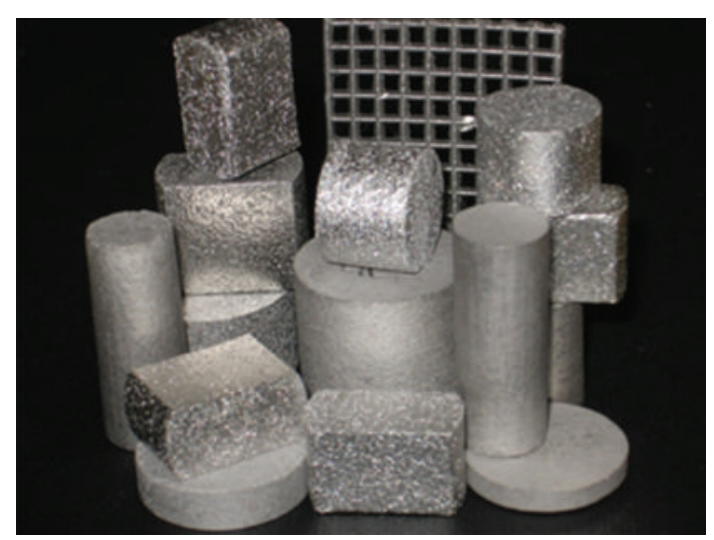

FIgURE 6: Ni-based dental alloy pellets.

the picture of homogeneous distribution of components representative for the alloy. Figure 6 shows images of densified by sintering dental alloy pellets produced on the basis of mechanically treated Ni-Cr powder mixtures.

The picture reveals the technological advantages and flexibility of the production method which includes mechanical treatment of component, densification by the methods of powder metallurgy and obtaining dense pellets having 99\% relative density, desired shape and weight. The pellets of the Ni-based alloy obtained in this way have perfect castability demonstrated by casting of a standard tiny lattice model and constant composition of the components [8]. It is very important to notice that the mechanical treatment of the alloy components results in a perfect homogeneity of the composition and morphological changes of metal particles associated with improved pressability and sinterability. The homogeneity of the powder mixture is inherited by ingots, thus ensuring constancy in the properties of the batch.

Figure 7 demonstrates the excellent technological and aesthetic properties of the alloy and the large possibilities to obtain highly complicated porcelain veneered dental constructions. The composition of the nickel-chromium dental alloy is well balanced which means that elements like $\mathrm{Si}, \mathrm{Mn}$, and $\mathrm{Ce}$ are present in amounts sufficient to improve some properties of the alloy without deteriorating others. For example, it is known that the presence of some amounts of $\mathrm{Mn}, \mathrm{B}$, and Ce improves the bonding strength

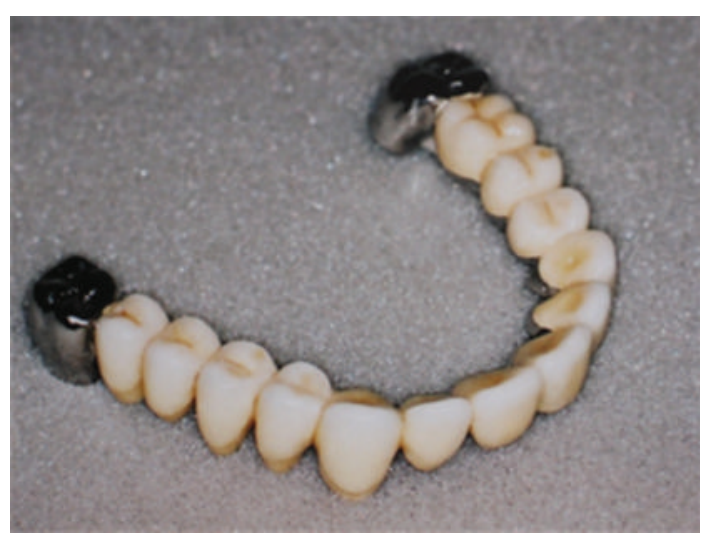

Figure 7: Metal-to-ceramic Ni-based dental construction.

between the alloy surface and porcelain veneer. At the same time, excess addition of $\mathrm{Mn}$ tends to decrease the corrosion resistance and aesthetic properties of the dental construction, discoloring the porcelain veneer. Furthermore, it is crucial that the B content does not exceed ca. 0.05$0.1 \mathrm{wt} . \%$ since it tends to increase the brittleness of the dental constructions. The same could be said for $\mathrm{Si}$, which in amounts exceeding $6 \mathrm{wt} . \%$ decreases the mechanical strength of the alloy. These examples clearly indicate the necessity of perfect homogenization of the alloy components, thus providing exact and constant composition of every ingot of the dental alloy. The precisely balanced composition of dental alloys is responsible for the combination of their mechanical, technological, and aesthetic properties. Among these properties the value of the linear coefficient of thermal expansion (CTE) is decisive for the compatibility between the ceramic veneer and metal construction. In order to produce compressive stress in the porcelain during cooling there is a general consensus that the alloy should have higher CTE than the porcelain [9-11]. The value of $13.9 \times 10^{-6} \times \mathrm{C}^{-1}$ in the temperature interval $25-600^{\circ} \mathrm{C}$ was determined by dilatometric tests and is similar to the data for most of the market available Ni-based dental alloys. In ductile materials, at some point, the stress-strain curve deviates from the straight-line relationship, and the Hooke's law no longer applies as the strain increases faster than the stress. From this point on, some permanent deformation in the specimen occurs, and the material is said to react plastically to any further increase in load or stress. That is why the level of the elongation limit $\left(R p_{0.2}\right)$ of nickel-chromium dental alloys is a very important mechanical characteristic showing the limit of their application. The standard mechanical tests after casting of ingots show mean value of $482 \mathrm{MPa}$. This value overcomes the elongation limit of most of the market available nickel-based alloys and is similar to that of some cobaltbased dental alloys which are generally stronger [12-14]. The alloy is characterized by tensile strength $(R m)$ of $670 \mathrm{MPa}$, low value of ductile yield (5\%), and Vickers hardness $\left(H V_{10}\right)$ of 220 units. The well-balanced composition, the chemical purity of the alloy components, and the high density of the dental ingots determine the high level of mechanical and technological properties of the alloy. It should be accentuated 


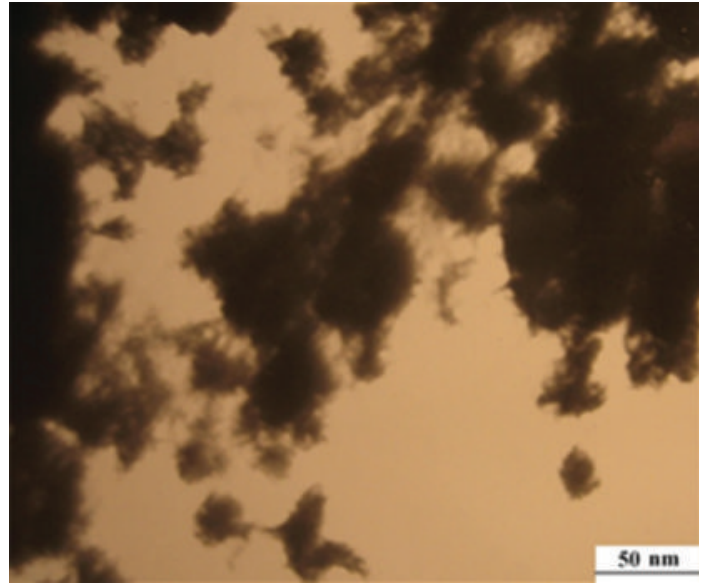

FIgURE 8: TEM of NiTi alloy obtained by mechanically assisted synthesis, $\times 200000$.

that these results were obtained in the absence of Be or other toxic additives to the alloy composition. The role of beryllium which often presents in small amounts (about $2 \mathrm{wt. \% )}$ in some base metal dental alloys is to lower the melting temperature and surface tension, thus facilitating castability and improving porcelain-metal bond strength [15-18]. It is believed that acting as a grain refiner, Be improves tensile strength and ductility of the alloy. However, exposure to beryllium vapor or particles is associated with a number of health risks from contact dermatitis to chronic lung disease, known as chronic beryllium disease (CBD). In addition, Be and its compounds in vapor or particulate form have been shown to be carcinogenic [19-21]. The exact composition of nickel-based dental alloys is decisive also for the biocompatibility and for the level of the nickel cations released from contact with the human saliva. Investigations in that area unambiguously show the mutual role of $\mathrm{Cr}$, Mo, and $\mathrm{Mn}$ on the formation of stable passive layer protecting from corrosion $[22,23]$. Here described new technique for dental alloy production allows obtaining nickel-based ingots with strict composition and constant set of mechanical, technological, and biological properties.

3.2. Mechanochemistry of NiTi Alloys. The mechanochemistry offers variety of synthesis methods like mechanically assisted thermal synthesis, mechanically assisted selfpropagating high-temperature synthesis, direct mechanical synthesis, and so forth. Figure 8 shows TEM image of NiTi alloy obtained after $30 \mathrm{~h}$ mechanical activation of equiatomic NiTi powder mixture and thermal synthesis at $550^{\circ} \mathrm{C}$ in a protective atmosphere of pure hydrogen for $30 \mathrm{~min}$.

The data of XRD analysis show presence of the equilibrium $\mathrm{TiNi}, \mathrm{Ti}_{2} \mathrm{Ni}$, and $\mathrm{TiNi}_{3}$ phases that limit the region of the system NiTi with respect to its practical application. The data obtained by XRD and SEM investigations show that the product consists of nanosized particles with mean size of $20-30 \mathrm{~nm}$ which form an aggregate mass $[6,24]$. Nanosized materials possess high sinterability due to their defect structure and large contact surface area resulting

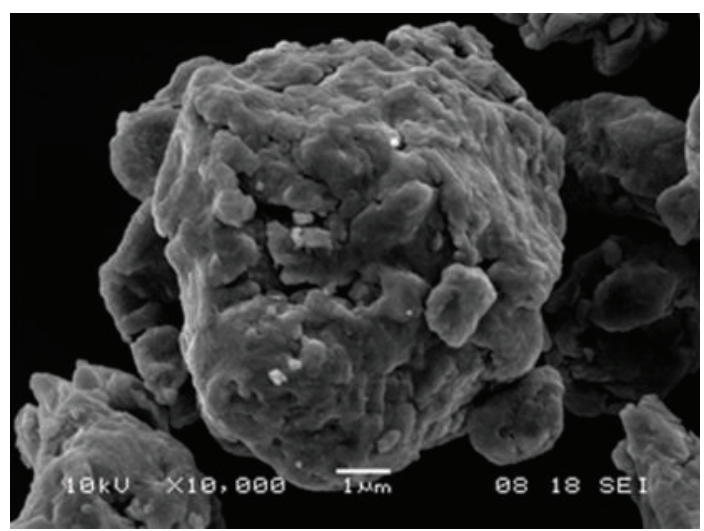

FIgure 9: SEM image of NiTi alloy obtained by direct mechanical synthesis, $\times 10000$.

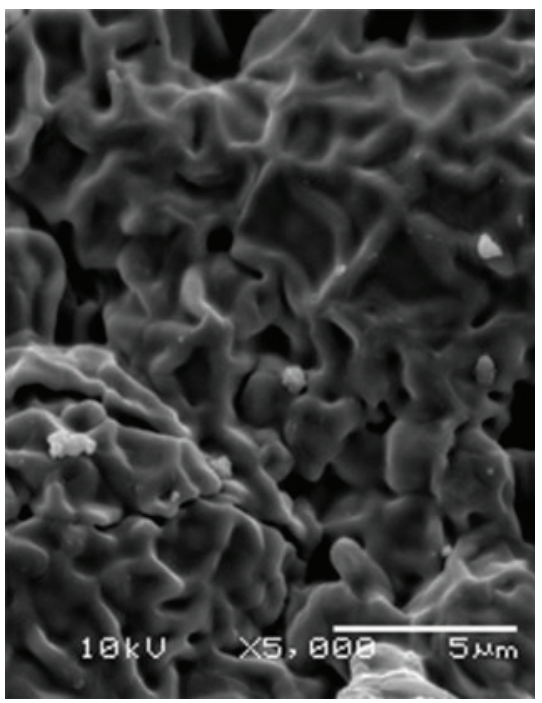

FIgure 10: SEM of sintered NiTi, $\times 5000$.

in enhanced diffusion mobility. The high activity of such materials allows producing macrosized end bodies at milder conditions, for example, by pressureless sintering or sintering at significantly lower temperatures. Prolonged milling time up to $40 \mathrm{~h}$ leads to direct synthesis of NiTi alloy which phase composition is similar to that of the product obtained by mechanically assisted thermal synthesis. Figure 9 shows SEM image of the product which forms globular aggregates typical of the products obtained by mechanical synthesis.

Being built of particles with submicron sizes, these aggregates have complicated structure, possess high sinterability, and are suitable to create dense bodies with controlled porosity. Similar porous structure with uniformly distributed pores being $1-2 \mu \mathrm{m}$ in size is shown in Figure 10 .

The material is densified by sintering at $800^{\circ} \mathrm{C}$ of NiTi powders obtained by direct mechanical synthesis. The possibility to obtain bodies with controlled porous structure is very important for the application of NiTi alloys in implantology. The presence of open interconnected pores with predetermined dimensions allows penetration of the human 
bone tissue into NiTi implants. That is a good example for creation of macroproducts with controlled properties due to the use of nanostructured particles [25].

\section{Conclusion}

The methods of mechanochemistry allow to overcome the difficulties of the traditional thermal alloying methods in synthesis of some Ni-based alloys with medical application. Powder metallurgical route in preparation of Ni-based alloys provides exact composition and random distribution of components in dental ingots and strict control of the nickeltitanium ratio which is decisive for the temperature range of martensite-austenite transformation of the NiTi SMAs. As a result of the intense mechanical treatment, the components of the alloys acquire good press and sinterability which allow, after cold pressing and sintering, producing bodies with controlled porosity. Applying the method of mechanically assisted sintering, high-quality beryllium-free dental alloy ingots, and finally complicated dental constructions could be produced [26]. The method of dental alloy production described here shows how to achieve perfect homogeneity and exact composition of every ingot and probably how to enlarge the area of application of the cheap nickel-containing dental alloys. In the case of $\mathrm{NiTi}$, the mechanical treatment of the reagents leads to a significant lowering of the synthesis temperature or to direct synthesis of nanosized alloy suitable for sintering bodies with controlled porosity.

\section{References}

[1] H. F. Morris, M. Manz, W. Stoffer, and D. Weir, "Casting alloys: the materials and clinical effects," Advances in Dental Research, vol. 6, pp. 28-31, 1992.

[2] M. Pretti, E. Hilgert, M. Bottino, and R. Avelar, "Evaluation of shear bond strength of the union between two Co-Cr alloys and a dental porcelain," Journal of Applied Oral Science, vol. 12, no. 4, pp. 280-284, 2004.

[3] K. Otsuka and T. Kakeshita, "Science and technology of shapememory alloys: new developments," MRS Bulletin, vol. 27, no. 2, pp. 91-100, 2002.

[4] K. Ebato, M. Tsuda, and T. Oomori, US Patent, 5,316,599, 1994.

[5] A. Szajek, M. Makowiecka, E. Jankowska, and M. Jurczyk, "Electrochemical and electronic properties of nanocrystalline $\mathrm{TiNi}_{1-x} \mathrm{M}_{x}(\mathrm{M}=\mathrm{Mg}, \mathrm{Mn}, \mathrm{Zr}, x=0,0.125,0.25)$ ternary alloys," Journal of Alloys and Compounds, vol. 403, no. 1-2, pp. 323328, 2005.

[6] D. D. Radev, "Mechanical synthesis of nanostructured titanium-nickel alloys," Advanced Powder Technology, vol. 21, no. 4, pp. 477-482, 2010.

[7] D. D. Radev and D. G. Klissurski, "Mechanochemical synthesis and SHS of diborides of titanium and zirconium," Journal of Materials Synthesis and Processing, vol. 9, no. 3, pp. 131-136, 2001.

[8] D. D. Radev and M. I. Marinov, Bg. Patent, 63728, 2002.

[9] P. De Hoff, K. Anusavice, and B. Hojjatie, "Thermal incompatibility analysis of metal-ceramic systems based on flexural displacement data," Journal of Biomedical Materials Research, vol. 41, pp. 614-623, 1998.
[10] T. R. Walton and W. J. O'Brien, "Thermal stress failure of porcelain bonded to a palladium-silver alloy," Journal of Dental Research, vol. 64, no. 3, pp. 476-480, 1985.

[11] S. C. Lopes, V. O. Pagnano, J. M. D. De Almeida Rollo, M. B. Leal, and O. L. Bezzon, "Correlation between metal-ceramic bond strength and coefficient of linear thermal expansion difference," Journal of Applied Oral Science, vol. 17, no. 2, pp. 122-128, 2009.

[12] “US Patent," 6613275, 2003.

[13] “US Patent," 6756012, 2001.

[14] “US Patent Application,” 0041820, 2002.

[15] K. F. Leinfelder, "An evaluation of casting alloys used for restorative procedures," Journal of the American Dental Association, vol. 128, no. 1, pp. 37-45, 1997.

[16] J. S. Covington, M. A. McBride, W. F. Slagle, and A. L. Disney, "Beryllium localization in base metal dental casting alloys," Journal of Biomedical Materials Research, vol. 19, no. 7, pp. 747-750, 1985.

[17] O. L. Bezzon, M. G. de Mattos, R. F. Ribeiro, and J. M. Rollo, "Effect of beryllium on the castability and resistance of ceramometal bonds in nickel-chromium alloys," The Journal of Prosthetic Dentistry, vol. 80, no. 5, pp. 570-574, 1998.

[18] H. H. Huang, M. C. Lin, T. H. Lee et al., "Effect of chemical composition of Ni-Cr dental casting alloys on the bonding characterization between porcelain and metal," Journal of Oral Rehabilitation, vol. 32, no. 3, pp. 206-212, 2005.

[19] M. Kuschner, "The carcinogenicity of beryllium," Environmental Health Perspectives, vol. 40, pp. 101-105, 1981.

[20] I. Fodor, "Histogenesis of beryllium-induced bone tumours," Acta Morphologica Academiae Scientiarum Hungaricae, vol. 25, no. 2-3, pp. 99-105, 1977.

[21] W. T. Sanderson, E. M. Ward, and M. R. Petersen, "Re: lung cancer case-control study of beryllium workers," American Journal of Industrial Medicine, vol. 39, pp. 133-144, 2001.

[22] J. D. Bumgardner and L. C. Lucas, "Surface analysis of nickelchromium dental alloys," Dental Materials, vol. 9, no. 4, pp. 252-259, 1993.

[23] S. B. Jones, R. L. Taylor, J. S. Colligon, and D. Johnson, "Effect of element concentration on nickel release from dental alloys using a novel ion beam method," Dental Materials, vol. 26, no. 3, pp. 249-256, 2010.

[24] R. A. Varin and Ch. Chiu, "Synthesis of nanocrystalline magnesium diboride $\left(\mathrm{MgB}_{2}\right)$ metallic superconductor by mechano-chemical reaction and post-annealing," Journal of Alloys and Compounds, vol. 407, no. 1-2, pp. 268-273, 2006.

[25] S. Kipp, V. Sepelak, and K. D. Becker, "Chemistry with the hammer: mechanochemistry," Chemie in Unserer Zeit, vol. 39, no. 6, pp. 384-392, 2005.

[26] D. D. Radev and M. I. Marinov, “Bg Patent,” 002045, 2012. 

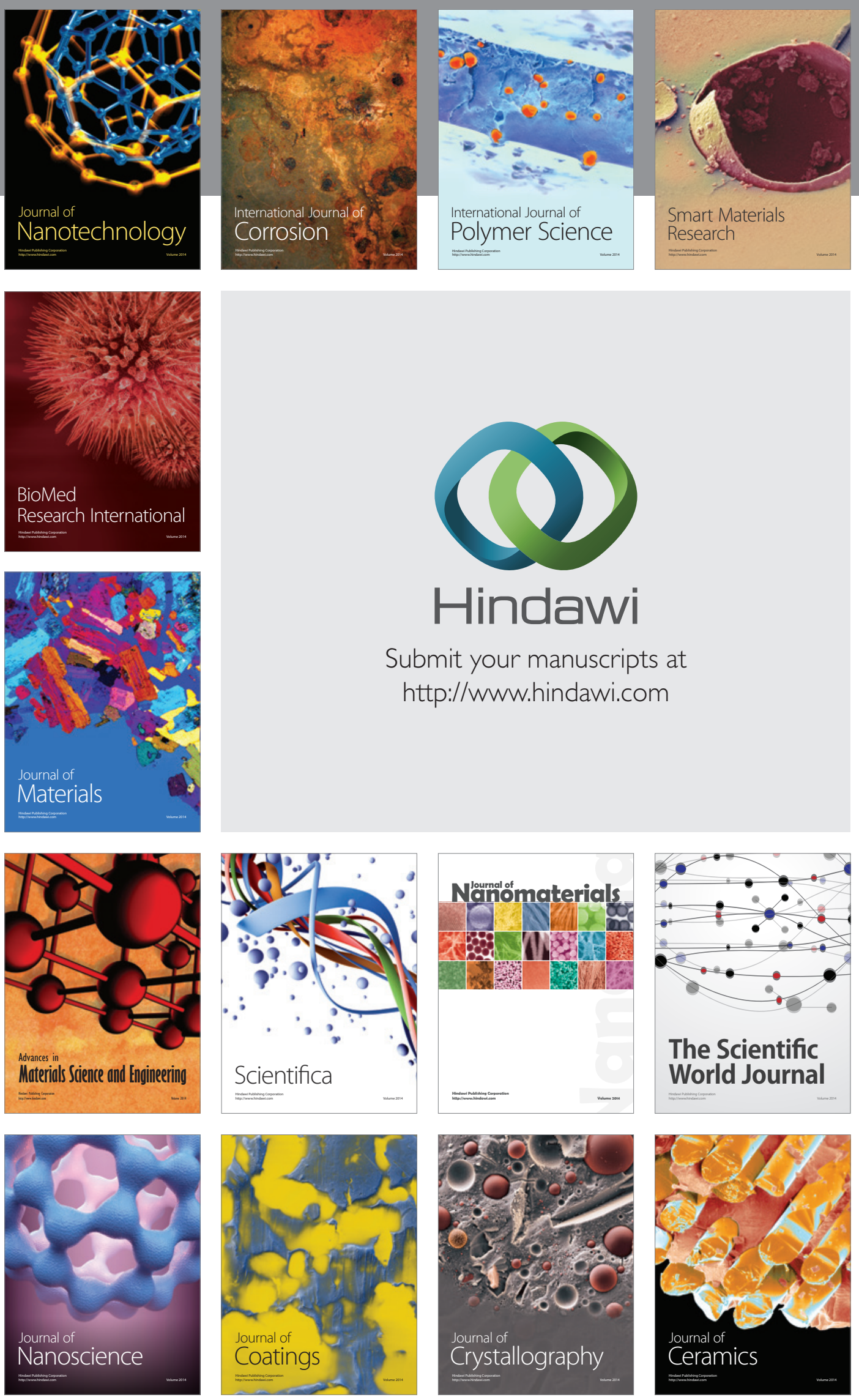

The Scientific World Journal

Submit your manuscripts at

http://www.hindawi.com

\section{World Journal}

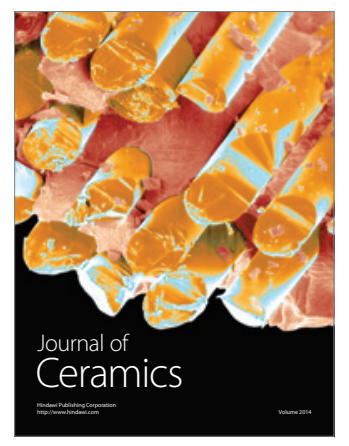

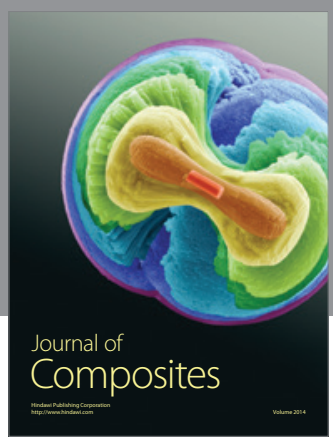
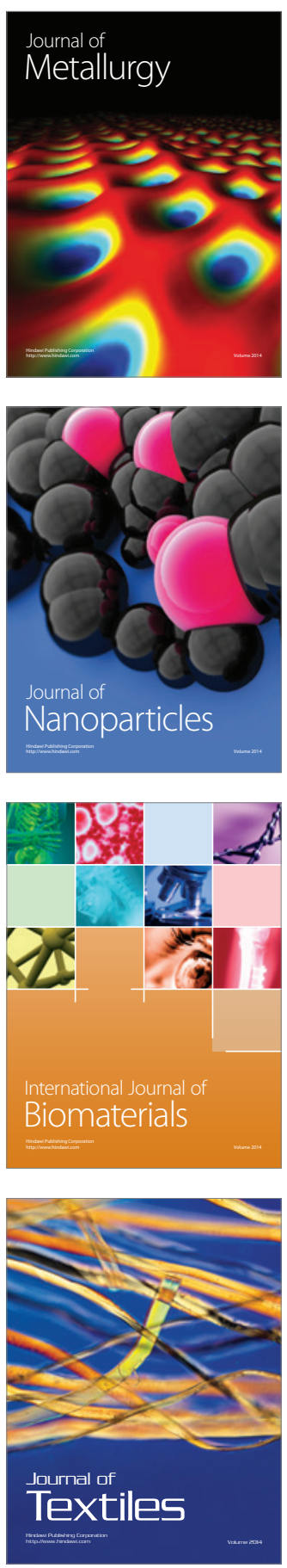